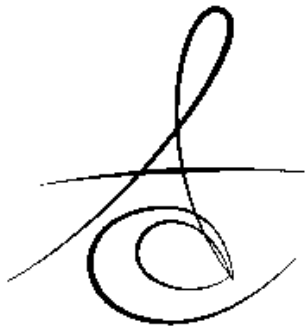

Arş. Gör. Dt. Süeda KARA*

\section{DİYETİN DENTAL EROZYON ÜZERİNE ETKİSİ}

EFFECTS OF DIET ON DENTAL EROSION

Makale Kodu/Article code: 2128

Makale Gönderilme tarihi: 10.02 .2015

Kabul Tarihi: 24.03.2015

\section{ÖZET}

Dental erozyon, bakteri içermeyen kimyasal bir olayla dental sert dokuların ilerleyici, geri dönüşümsüz kaybı olarak tanımlanmaktadır. Yaşam tarzları ve diyet alışkanlıklarının değişimi ile dişlerde erozyon görülme sıklığı giderek artmaktadır. Erozyon dişlerde hassasiyet, çiğnemede problem, oklüzyon düşüklüğü, kötü estetik, pulpa ekspozu ve apseler gibi birçok klinik probleme neden olmaktadır. Yiyecek ve içeceklerin özellikleri ile bireysel alışkanlıklar dental erozyonun gelişiminde rol oynamaktadır. İçeceklerin eroziv kapasitesi asidite, ph değeri, fosfat ve flor içeriği, asidin tipi, tamponlama ve titrasyon kapasitesi, sıcaklık gibi birçok faktöre bağlıdır. Yiyecek ve içeceklerin, diş yüzeyi ile temas süresinin azalması eroziv etkilerini minimuma indirmektedir. $\mathrm{Bu}$ derlemenin amacı çocuklarda diyet ve dental erozyon ilişkisini incelemektir.

Anahtar kelimeler: dental erozyon, diyet, asidik içecekler

\section{GİRIŞ}

Dental erozyon, bakteri içermeyen kimyasal bir olayla dental sert dokuların ilerleyici, geri dönüşümsüz kaybı olarak tanımlanmaktadır. ${ }^{1-4}$ Günümüzde yaşam tarzları ve diyet alışkanlıklarının değişimi ile dişlerde erozyon görülme sıklığı artmaktadır. ${ }^{5,6}$ Erozyon dişlerde hassasiyet, çiğnemede problem, oklüzyon düşüklüğü, kötü estetik, pulpanın açığa çıkması ve apseler gibi birçok klinik problemi ortaya çıkarmaktadır. ${ }^{1}$

Yapılan çalışmalarda erozyon görülme sıklığının \%7-57 arasında olduğu belirtilmektedir. ${ }^{7-13}$ Erozyon birçok faktöre bağı ortaya çıkmaktadır. ${ }^{14-18}$ Asitli yiyecek ve içeceklerin erozyona neden olduğu bilinmek-

\section{ABSTRACT}

Dental erosion defined as a bacteria free chemical event that progressive and irreversible loss of dental hard tissues. Encountering of dental erosion is increasing through change in lifestyle and dietary habits. Erosion can cause sensitivity of teeth, chewing problem, loss of vertical dimension, poor esthetic, expose of pulp chamber, and dental abscesses. The characteristics of foods and beverages and individual habits play important role in dental erosion. Erosive capacity of beverage depends on various factors such as acidity, ph, phosphate and fluoride content, type of acid, buffering and titration capacity, temperature. Reduced contact time between acidic food/beverages and tooth surface may minimize the erosive effect. The goal of this review is to investigate the relationship between diet and dental erosion in children.

Keywords: dental erosion, diet, acidic beverages

tedir. ${ }^{18}$ Erozyonun erken evrelerinde diş yüzeyi pürüzsüz, ipeksi parlak olarak izlenmektedir. Klinik bulguları diş yüzey anatomisi kaybı, insizal translüsensi artışı, mine dokusunun azalması ve insizal kenarın aşınmasıdır. ${ }^{1}$ Erozyon ilerledikçe oklüzal morfoloji bozulmaktadır. Alınan gıdalara bağı olarak gelişen eroziv lezyonların özellikle ön dişlerin labiyal yüzeylerinde olduğu bildirilmektedir. ${ }^{19}$ Birçok çalışmada erozyondan en fazla üst çene kesici dişlerin etkilendiği belirtilmektedir. ${ }^{9,13,20}$

Erozyon, klinik olarak deneyimli bir hekim tarafından teşhis edilebilmektedir. Erozyonu değerlendirmek için literatürde birçok indeks kullanılmıştır. ${ }^{21-23}$ Bu derlemenin amacı dental erozyon ile diyet ilişkisini incelemektir.

*̇zmir Katip Çelebi Üniversitesi, Diş Hekimliği Fakültesi, Pedodonti Anabilim Dal

${ }^{* *}$ Ege Üniversitesi, Diş Hekimliği Fakültesi, Pedodonti Anabilim Dalı 


\section{EROZYON VE DİYET İLİ̧̧Kİsí}

Diyet ve dental erozyon arasındaki ilişki in vitro, in vivo, deneysel çalışmalar ve hayvan çalışmalarında gösterilmektedir. Thomas'ın diş hekimliği öğrencilerinde yaptığı bir çalışmada 6 hafta süre ile her gün kola, greyfurt suyu ve portakal suyu içildiğinde özellikle greyfurt suyu tüketen bireylerin dişlerinin labiyalinde erozyon bulgularına rastlanmıştır. ${ }^{24}$ Stabholz ve arkadaşları yaptıkları bir çalışmada $10-18$ ay boyunca her gün portakal suyu içen çocukların eksfoliye süt dişlerinde demineralizasyon bulgusuna ulaşmışlardır. ${ }^{25}$ Epidemiyolojik çalışmalar erozyon ile sirke, turşu, turunçgil ve meyve suyu gibi gıdaların tüketimi ara- sında ilişki olduğunu göstermektedir. ${ }^{26}$ Ayrıca asidik yiyecek ve içeceklerin alım sıklığının tüketilen miktardan daha etkili olduğu ve erozyonun ağız hijyeni iyi olan bireylerde daha fazla görüldüğü bildirilmektedir. ${ }^{27}$ Jarvinen ve arkadaşlarının yaptıkları çalışmada günde ikiden fazla narenciye, haftada birden fazla sirke veya spor içeceği tüketimi olanlarla erozyon görülme sıklığı arasında ilişki olduğu belirtilmektedir. ${ }^{28}$ Deneysel klinik çalışmalarda asidik içecekler ile ağız sıvılarının ph'ının düştüğü ve bu durumun en çok greyfurt tüketiminde olduğu belirtil- mektedir. ${ }^{24}$ Yapılan bir çalışmaya göre meyve sula- rının meyvelere göre 3-10 kat daha eroziv olduğu bildirilmektedir. ${ }^{29}$

\section{İçeceklerin özelliklerinin dental erozyon üzerine etkisi}

İçeceklerin eroziv kapasitesi asidite, ph değeri, fosfat ve flor içeriğine bağlıdır. ${ }^{30,}{ }^{31}$ Erozyonu etkileyen diğer faktörler arasında asidin tipi, tamponlama ve titrasyon kapasitesi ve sıcaklık sayılabilmektedir. ${ }^{32}$ Yüksek ph'lı, düşük titrasyon kapasiteli ve yüksek kalsiyum, fosfor, flor konsantrasyonuna sahip içeceklerde erozyon potansiyeli azalmaktadır. ${ }^{33}$ Diş yüzeyi ile temas süresi de içeceklerin eroziv potansiyelini etkileyen faktörlerdendir. ${ }^{30}$ Asidik içeceklerin uzun süre diş yüzeyi ile teması halinde eroziv etkilerinin daha fazla olduğu bildirilmiştir. ${ }^{34}$ İçeceklerin tüketim şekli de diş yüzey ph'ını etkilemektedir. Johanson ve arkadaşları ağızda tutma, kısa süreli yudumlama, uzun süreli yudumlama, hızla yutma, pipetle tüketme ve biberonla tüketmenin erozyonla ilişkilerini araştırmışlardır. ${ }^{35}$ İçeceklerin pipet ile alınmasıyla sıvının dişler üzerine yayılımı sınırlandırılabilmekte ve minimum temas sağlanabilmektedir. ${ }^{36}$
Asidin tipi ve konsantrasyonu sadece ph'ı değil tamponlama özelliklerini de etkilemektedir. Rugg-Gunn ve Nunn fosforik asidin ph'ının düşmesiyle daha eroziv etkili olduğunu bildirmektedir. Sitrik asit, maleik asit ve tartarik asidin fosforik aside göre daha yüksek ph'larda kalsiyumla şelasyon gösterme özelliği bulunduğu belirtilmektedir. ${ }^{37}$ West ve arkadaşları aynı ph'lardaki sitrik asidin, fosforik aside göre daha eroziv olduğunu bildirmektedir. ${ }^{38}$ Khamverdi ve arkadaşları, 2013 yılında diyet kola ve normal kolanın eroziv potansiyellerini karşılaştırdıkları bir çalışmada, diyet kolanın normal koladan daha eroziv olduğunu rapor etmişlerdir. Bu durumun diyet kolanın yapısındaki sitrik asidin kalsiyuma bağlanma etkisinin güçlü olmasına bağlı olabileceği savunulmaktadır. ${ }^{6}$

Sıcaklık da içeceklerin eroziv potansiyelini etkilemektedir. Eisenburger ve Addy'nin çalışmasına göre erozyon derinliği asit ısısı arttıkça artmaktadır. ${ }^{39}$ Khamverdi ve arkadaşları kolanın oda sıcaklığı ile buzdolabı sıcaklığında eroziv etkilerini inceledikleri çalışmalarında istatiksel olarak anlamlı bir fark bildirmemektedir. $^{6}$

İçeceklerin akıcılığı ile erozyon ilişkisinin değerlendirildiği bir çalışmada sitrik asit (ph:3,2) farklı akıcılıklarda 20 dakika boyunca uygulandığında erozyon derinliğinin süre ve akıcılıkla doğru orantılı olarak arttığı belirlenmiştir. ${ }^{30}$

İçeceklerin yoğunluğunun da eroziv potansiyellerini etkileyebileceği ileri sürülmektedir. Yoğunluk ortalama ph üzerinde az bir etkide bulunurken, daha yoğun içeceklerde titre edilebilen asit kapasitesi düşmektedir. ${ }^{30}$

Daha iyi titrasyon kapasitesi ve tamponlama kapasitesi ile tükürüğün daha uzun süre nötralizasyon sağlayacağı bildirilmektedir. ${ }^{6}$

Asitlerin titre edilebilir olması ph'a göre erozyonu daha çok etkileyen bir faktör olarak bildirilmektedir. ${ }^{39}$

\section{Bireye ait faktörlerin dental erozyon üzerine etkisi}

Tükürüğün birçok özelliği ile dental erozyona karşı koruyucu etkisi olduğu bilinmektedir. Bunlar:

$\checkmark$ Eroziv ajanların dilüsyonu ve temizlenmesi,

$\checkmark$ Diyet asitlerinin nötralizasyonu ve tamponlanması,

$\checkmark$ Diş yüzeyinde kalsiyum ve fosfata doygun olan bir alan oluşturma,

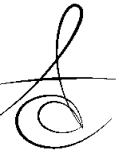


$\checkmark \quad$ Diyet asitleri ile demineralizasyonu engelleyen pelikılı oluşturmaktır. ${ }^{30}$

Yumuşak dokuların anatomisi ve fizyolojik hareketleri de dişlerdeki madde kayıplarını etkilemektedir. ${ }^{38}$ Egzersiz vücut sıvılarının azalmasına ve dehidratasyona böylece tükürük akışında azalmaya neden olabilmektedir. Ayrıca SIVı alım intiyacının artmasıyla kişi düşük ph'lı içeceklere yönelebilmektedir. Bu durum erozyon görülme olasılığını arttırmaktadır. ${ }^{30}$

Erozyon ile sosyoekonomik düzeyin ilişkisinin değerlendirildiği bir çalışmada 4 yaşındaki düşük sosyoekonomik düzeyli bireylerde yüksek sosyoekonomik düzeyli bireylere göre daha az erozyon gözlenmektedir. ${ }^{40}$ Araştırmacilar bu durumun sosyoekonomik düzey arttıkça bireyin asidik yiyecek ve içeceklere ulaşımının kolaylaşmasına bağlı olabileceğini vurgulamaktadır. ${ }^{41}$

Yapılan çalışmalara göre narenciye tüketimi sonrası diş yüzey kaybı diş fırçalama ile artmaktadır. ${ }^{32}$ Levitch ve arkadaşları'na göre asidik yiyecek ve içecek tüketiminin hemen sonrasında diş fırçalamanın erozyon ve abrazyonun sinerjik etkisiyle çürüksüz lezyonlara sebep olabileceği ileri sürülmektedir. ${ }^{42}$ Asidik yiyecek ve içecek tüketimini takiben 30 dakika içerisinde dişlerin fırçalanmasının erozyon oluşma riskini arttırdığı belirtilmektedir. ${ }^{43}$

Diş çürüğü ile erozyon arasında anlamlı bir ilişki olduğunu bildiren çalışmaların yanında ${ }^{44,45}$ herhangi bir ilişki olmadığını gösteren çalışmalar da bulunmaktadır. ${ }^{46,47}$

Sonuç olarak;

- Erozyonun önlenmesi için dişlere asidin ulaşması engellenmeli ve asidik yiyecek ve içeceklerin günlük tüketimi sınırlandırımalıdır.

- Asidik yiyecek ve içeceklerin tüketim şekline dikkat edilmeli ve dişlerle minimum temas sağlanmalıdır.

- Asidik gidaların gün sonunda en son yenen şey olmasından kaçınıımalıdır.

- Asidik yiyecek ve içeceklerin tüketiminden hemen sonra diş fırçalanmasından kaçınıımalıdır.

- Sakızlar tükürük akışını arttırdığı için gastroözofageal reflü (GÖR) hastalığı olmayan bireylerde kullanımı önerilmelidir.

- Hastalardan diyet listesi alınmalı ve bu sayede alınan asitli gıdalar sınırlandırımalıdır.

- Hastalar rutin diş hekimi kontrollerine çağırılarak erozyonun önüne geçilmeye çalışılmalıdır. ${ }^{30}$
Tüm bunlara rağmen erozyon meydana gelmiş ise; herhangi bir semptom yoksa koruyucu uygulamalar önerilmektedir. Eğer hastanın şikayetleri varsa, süt dişlerinin restorasyonunda kompomer, cam iyonomer siman ve paslanmaz çelik kronlar kullanılmaktadır. Erozyona uğramış daimi dişlerde; kompozit restorasyonlar ya da estetik kronlar yapılabilmektedir. Erozyonun pulpaya kadar ilerlediği durumlarda endodontik tedavi ya da diş çekimi yapılabilmektedir. ${ }^{30}$

\section{KAYNAKLAR}

1- Taji S, Seow WK. A literature review of dental erosion in children. Aust Dent J 2010;55:358-67.

2- Li H, Zou Y, Ding G. Dietary factors associated with dental erosion: a meta-analysis. PLoS One 2012;7:e42626.

3- Jaervinen VK, Rytömaa IJ, Heihonen OP. Risk factors in dental erosion. J Dent Res 1989;68:1275-8.

4- Okunseri C, Okunseri E, Gonzalez C, Visotcky A, Szabo A. Erosive tooth wear and consumption of beverages among children in the United States. Caries Res 2011;45:130-5.

5- Wang $X$, Lussi A. Functional foods/ingredients on dental erosion. Eur J Nutr 2012;51:39-48.

6- Khamverdi Z, Vahedi M, Abdollahzadeh S, Ghambari MH. Effect of a common diet and regular beverage on enamel erosion in various temperatures: an in-vitro study. J Dent 2013; 10:411-6.

7- Milosevic A, Bardsley PF, Taylor S. Epidemiological studies of tooth wear and dental erosion in 14year-old children in North West England. Part 2: The association of diet and habits. Br Dent J 2004; 197:479-83;

8- Peres KG, Armenio MF, Peres MA, Traebert J, De Lacerda JT. Dental erosion in 12-year-old schoolchildren: a cross-sectional study in Southern Brazil. Int J Paediatr Dent 2005;15:249-55.

9- Auad SM, Waterhouse PJ, Nunn JH, Steen N, Moynihan PJ. Dental erosion among 13- and 14year-old Brazilian schoolchildren. Int Dent J 2007; 57:161-7.

10-Peres KG, Armenio MF, Peres MA, Traebert J, De Lacerda JT. Dental erosion in 12-year-old schoolchildren: a cross-sectional study in Southern Brazil. Int J Paediatr Dent 2005;15:249-55. 
11-Abu-Ghazaleh SB, Burnside G, Milosevic A. The prevalence and associated risk factors for tooth wear and dental erosion in 15- to 16-year-old schoolchildren in Amman, Jordan. Eur Arch Paediatr Dent 2013;14:21-7.

12-Vargas-Ferreira F, Praetzel JR, Ardenghi TM. Prevalence of tooth erosion and associated factors in 11-14-year-old Brazilian schoolchildren. J Public Health Dent 2011;71:6-12.

13-Dugmore CR, Rock WP. A multifactorial analysis of factors associated with dental erosion. Br Dent J 2004;196:283-6.

14-Imfeld T. Dental erosion definition, classification and links. Eur J Oral Sci 1996;104:151-5.

15- O'Sullivan E, Milosevic A, British Society of Paediatric D. UK National Clinical Guidelines in Paediatric Dentistry: diagnosis, prevention and management of dental erosion. Int J Paediatr Dent 2008;18:29-38.

16-Scheutzel P. Etiology of dental erosion--intrinsic factors. Eur J Oral Sci 1996;104:178-90.

17-Aine L, Baer M, Maki M. Dental erosions caused by gastroesophageal reflux disease in children. ASDC J Dent Child. 1993;60:210-4.

18-Gandara BK, Truelove EL. Diagnosis and management of dental erosion. J Contemp Dent Pract 1999;1:16-23.

19-Jarvinen V, Rytomaa I, Meurman JH. Location of dental erosion in a referred population. Caries Res 1992; 26: 391-96.

20-Aguiar YP, dos Santos FG, Moura EF, da Costa FC, Auad SM, de Paiva SM, et al. Association between dental erosion and diet in Brazilian adolescents aged from 15 to 19: a population-based study. J Public Health Dent 2009; 69:254-9

21-Wiegand A, Muller J, Werner C, Attin T. Prevalence of erosive tooth wear and associated risk factors in 2-7-year-old German kindergarten children. Oral Dis 2006;12:117-24.

22-Larsen IB, Westergaard J, Stoltze K, Larsen AI, Gyntelberg F, Holmstrup P. A clinical index for evaluating and monitoring dental erosion. Community Dent Oral Epidemiol 2000;28:211-7.

23-Khan F, Young WG, Law V, Priest J, Daley TJ. Cupped lesions of early onset dental erosion in young southeast Queensland adults. Aust Dent J 2001;46:100-7.
24-Thomas AK. Further observations on the influence of citrus fruit juices on human teeth.NY State Dent J 1957;23:424-30.

25-Stabholz A, Raistein J, Markitziu A, Galon H, Giter R, Forenstein E, Srougi I, Bohrer J, Gedalia I. Tooth enamel dissolution from erosion or etching and subsequent caries development. J Pedod 1983;7:100-8

26-Linkosalo $E$, Markkanen $H$. Dental erosions in relation to lactovegetarian diet. Scand J Dent Res 1985;93:436-41.

27-Millward A, Shaw L, Smith AJ, Rippin JW, Harrington E.The distribution and severity of tooth wear and the relationship between erosion and dietary constituents in a group of children Int J Paediatr Dent 1994;4:151-7.

28-Jarvinen VK, Rytomaa II, Heinonen OP.Risk factors in dental erosion. J Dent Res 1991;70:942-7.

29-McCAY CM, Will L. Erosion of molar teeth by acid beverages. J Nutr 1949;39:313-24.

30-Bamise CT, Kolawol KA, OloyedeEO. The determinants and control of soft drinks-incited dental erosion. J Dent Clin Res 2009;5:141-54.

31-Lussi A, Jaggi $T$, Schärer $S$. The influence of different factors on in vitro enamel erosion. Caries Res 1993;27:387-93.

32-Hughes JA, West NX, Parker DM, Newcombe RG, Addy M. Development and evaluation of a low erosive blackcurrant juice drink in vitro and in situ. 1. Comparison with orange juice. J Dent 1999;27:285-9.

33-Milosevic A. Sports drinks hazard to teeth. Br J Sports Med 1997;31:28-30.

34-Zero D, Lussi A. Behavioral factors. Monogr Oral Sci 2006;20:100-5.

35-Johanson AK, Lingström P, Imfeld T, Birkhed D. Influence of drinking method on tooth-surface $\mathrm{pH}$ in relation to dental erosion. Eur J Oral Sci 2004;112:484-9.

36-Edwards M, Ashwood RA, Littlewood SJ, Brocklebank LM, Fung DE. A videofluoroscopic comparison of straw and cup drinking: the potential influence on dental erosion. $\mathrm{Br}$ Dent J 1998;185:244-9.

37-Rugg-gunn AJ,Nunn JH.Diet and dental erosion.Nutrition, diet and oral health. Oxford University Press, 1999. p. 198

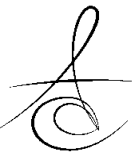


38-West NX, Hughes JA, Addy M. The effect of $\mathrm{pH}$ on the erosion of dentine and enamel by dietary acids in vitro. J Oral Rehabil 2001;28:860-4.

39-Eisenburger $M$, Addy $M$. Influence of liquid temperature and flow rate on enamel erosion and surface softening. J Oral Rehabil 2003;30:1076-80.

40-Moss SJ. Dental erosion. Int Dent J 1998;48:52939.

41-Millward A, Shaw L, Smith A. Dental erosion in four-year-old children from differing socioeconomic backgrounds. ASDC J Dent Child 1994;61:263-6.

42-Levitch LC, Bader JD, Shugars DA, Heymann HO. Non-carious cervical lesions. J Dent 1994;22:195207.

43-Kamak H, Alkan F, Okay TC, Erten H. Çeşitli İçeceklere Maruz Bırakılan Kompozit Rezinlerin Ağartıcı Diş Macunu İle Fırçalandıkdan Sonra Mikropürüzlülüğünün Değerlendirilmesi. Atatürk Üniv Diş Hek Fak Derg 2013;3:331-6.

44-Al-Malik MI, Holt RD, Bedi R Erosion, caries and rampant caries in preschool children in Jeddah, Saudi Arabia. Community Dent Oral Epidemiol 2002;30:16-23.

45-Kazoullis S, Seow WK, Holcombe T, Newman B, Ford D. Common dental conditions associated with dental erosion in schoolchildren in Australia. Pediatr Dent 2007;29:33-9.

46-Auad SM, Waterhouse PJ, Nunn JH, Moynihan PJ. Dental caries and its association with sociodemographics, erosion, and diet in schoolchildren from southeast Brazil Pediatr Dent 2009;31:229-35.

47-Truin GJ, van Rijkom HM, Mulder J, van't Hof MA. Caries trends 1996-2002 among 6- and 12-yearold children and erosive wear prevalence among 12-year-old children in The Hague. Caries Res 2005;39:2-8.

\section{Yazışma Adresi}

Dt.Süeda KARA

İzmir Kâtip Çelebi Üniversitesi,

Diş Hekimliği Fakültesi,

Pedodonti A.D. Aydınlık Evler Mahallesi, Cemil Meriç Caddesi, 6780 Sokak. No:48, 35640-Çiğli/İZMİR

Tel: +90 (232) 3254040

e-mail: dt.suedaka @gmail.com 